\title{
EVALUATION OF IMPLEMENTATION OF CLOUD COMPUTING in PT. SUPRANUSA SINDATA
}

\author{
Andika Ramadhan \\ Program Studi Informatika \\ FakultasTeknik UniversitasMuhammadiyahTangerang \\ J1. PerintisKemerdekaan 1/33 Cikokol Kota Tangerang \\ andika020888@gmail.com
}

\begin{abstract}
THE RESEARCH OBJECTIVES in this thesis is as evaluation of the implementation of Cloud Computing which has been in implementation in PT. Supranusa Sindata in order to develop into better again. METHODS were used in this study include the collection of journals and books as reference or grounding in analyzing. Data obtained from questionnaires to 100 respondents. The data were analyzed using factor analysis method after continued using regression analysis and designed with the IT Balanced Scorecard method. RESULTS OBTAINED is a form factor that can be used by PT. Supranusa Sindata to evaluate the implementation of Cloud Computing, technique systems engineering factors of cloud computing, cloud computing system management, performance measurement system of cloud computing, cloud computing system effectiveness. CONCLUSION with the model that can be used to evaluate the implementation of cloud computing and the design of strategic performance measurement using IT Balanced Scorecard is expected to grow so will affect the company's business performance and increase employee knowledge.
\end{abstract}

Keywords : Implementation Cloud Computing, Evaluation, Factor Analysis, Regression Analysis, IT Balanced

\section{PENDAHULUAN}

Perkembangan dari bisnis yang sangat cepat menuntut perubahan yang harus terjadi di organisasi, Dimana setiap organisasi berusaha dengan menggunakan cara untuk dapat bersaing dalam bisnis yang ada dan meningkatkan keuntungan bisnis. Teknologi sistem informasi merupakan hasil rekayasa manusia terhadap proses penyampaian informasi agar lebih cepat, hak akses terhadap informasi yang lebih luas,dan penyimpanan yang lebih mudah dan aman. Persaingan dalam bisnis, dan ekonomi menjadikan teknologi informasi banyak digunakan untuk mendukung kegiatan, dan aktifitas perusahaan. Salah satu kemajuan teknologi sistem informasi yang terbaru saat ini adalah Cloud Computing.

PT. Supranusa Sindata adalah penyedia solusi bisnis internasional untuk industri perhotelan,ritel dan rekreasi. Adapun tujuan bisnis dari PT.Supranusa Sindata adalah keberhasilan klien tergantung pada software yang tepat. Oleh karena itu PT. Supranusa Sindata mempunyai solusi professional untuk menyediakan software VHP (Visual Hotel Program) yang tepat bagi keberhasilan terhadap pelanggan. Menggunakan solusi PT.Supranusa Sindata Property Management mampu memberikan layanan terhadap pelanggan menjadi lebih baik untuk mencapai peningkatan efisiensi operasional, manajemen dan kontrol operasional.

Saat ini PT.Supranusa Sindata telah melakukan implementasi cloud computing terhadap sistem VHP (Visual Hotel Program) perhotelan. Dengan adanya implementasi cloud computing sistem VHP (Visual Hotel Program) perhotelan mengalami suatu perubahan baik secara investasi bisnis terhadap IT maupun kinerja operasional pada client dan pelayanan terhadap client. Oleh karena itu perlu dilakukan suatu evaluasi implementasi cloud computing agar dapat mendukung suatu keputusan terhadap proses bisnis pada PT.Supranusa Sindata.

Dimana dalam pengevaluasian sistem cloud computing seorang pemimpin harus dapat memerhatikan beberapa hal yaitu nilai investasi yang diterapkan, kinerja karyawan dalam menghadapi implementasi sistem dan pelayanan yang baik terhadap implentasi sistem yang sudah berjalan. Keberhasilan suatu perusahaan dalam mengelola usahanya salah satunya ditentukan dengan melihat bagaimana sikap pelanggan terhadap pelayanan yang diberikan oleh perusahaan tersebut.

\section{METODOLOGI PENELITIAN}

Metodologi yang digunakan dalam penelitian ini adalah menggunakan analisis faktor dan pengukuran terhadap sistem evaluasi Cloud Computing 
menggunakan IT Balanced Scorecard. Berikut tahapan penelitian yang dilakukan:

1. Tahap pertama

Menentukan faktor apa saja yang akan digunakan untuk mengevaluasi implementasi Cloud Computing. Faktor tersebut adalah:
a. Faktor Technology.
b. Faktor Organizatation.
c. Faktor Environment.

2. Tahap kedua

Setelah mendapatkan faktor yang dapat digunakan untuk evaluasi implementasi Cloud Computing, maka selanjutnya dilakukan analisis terhadap faktor tersebut untuk mendapatkan indikator-indikator apa saja yang dapat digunakan untuk mendapatkan nilai dalam mencari informasi.

3. Tahap Ketiga

Data kuesioner yang telah diberikan kepada responden dikumpulkan, setelah itu data dianalisis dengan tujuan mendapatkan indicator dan faktor baru yang dapat memepengaruhi evaluasi implementasi Cloud Computing di PT. Supranusa Sindata.

4. Tahap Keempat

Setelah mendapatkan faktor baru yang dapat mempengaruhi evaluasi implementasi Cloud Computing, dari hasil analisis tersebut dibuat suatu rancangan IT Balanced Scorecard untuk mengukur suatu sistem Virtual Hotel Program yang telah dimplementasi Cloud Computing dan dapat menghasilkan sebuah kesimpulan yang akan dijadikan saran kepada pihak PT.Supranusa Sindata untuk meningkatkan kualitas Sistem Virtual Hotel Program yang telah di implementasi Cloud Computing dalam rangka meningkatkan kinerja operasional,produktivitas karyawan dan kepuasan terhadap pelanggan pada proses bisnis di perusahaan.

\section{Results andDiscussion}

Dari hasil analisis faktor dapat diketahui indikatorindikator yang mempengaruhi evaluasi implementasi Cloud Computing di PT.Supranusa Sindata. Setelah melakukan analisa faktor terhadap data yang didapat, terbentuklah faktor dan indikator yang baru untuk meningkatkan kualitas Sistem Virtual Hotel Program yang telah di implementasi Cloud
Computing. faktor-faktor baru tersebut akan digunakan untuk mengevaluasi implementasi Cloud Computing di PT. Supranusa Sindata. Berikut ini adalah Faktor dan indikator baru yang terbentuk:

Faktor baru pertama, terdiri dari indikator:

1. Environment1 = Keputusan pemimpin perusahaan terhadap implementasi cloud computing dapat mendukung bisnis perusahaan.

2. Environment $2=$ Model kemampuan cloud computing yang sangat teknis akan berpengaruh terhadap lingkungan bisnis perusahaan.

3. Organization8 $=$ Keterampilan karyawan pada organisasi dibutuhkan terhadap implementasi cloud computing.

4. Environment4 = Peraturan penyimpanan data sudah sesuai dengan peraturan pelayanan cloud computing.

5. Environment 3 = Terdapat beberapa aspek cloud computing mempengaruhi persaingan pasar.

6. Organization9 = Implementasi Cloud Computing menggeser risiko bisnis seperti kegagalan dalam hardware dan pemeliharaan hardware.

7. Environment5 = Implementasi cloud computing harus mempunyai keamanan yang baik sehingga dapat berpengaruh pada proses bisnis di perusahaan.

8. Organization $3=$ Implementasi cloud computing dapat memberikan keuntungan terhadap bisnis perusahaan

Faktor baru kedua, terdiri dari indikator berikut:

1. Technology $2=$ Ketersediaan sistem yang baik akan mendukung proses aplikasi pada kesuksesan implementasi cloud computing

2. Technology $3=$ Konsistensi data pada sistem akan mendukung kesuksesan implementasi cloud computing

3. Technology $4=$ Konektivitas jaringan yang efektif akan mendukung kesuksesan implementasi cloud computing.

4. Technology $1=$ Keamanan sistem yang baik dapat mendukung kesuksesan implementasi cloud computing.

5. Technology5 = Implementasi cloud computing dapat mempengaruhi kinerja sistem aplikasi.

6. Technology6 = implementasi cloud computing dapat mengurangi biaya sumberdaya terhadap tekhnologi. 
Faktor baru ketiga, terdiri dari indikator berikut:

1 Technology9 = Konsistensi data pada sistem akan mendukung kesuksesan implementasi cloud computing

2. Technology10 = Konektivitas jaringan yang efektif akan mendukung kesuksesan implementasi cloud computing.

3. Technology7 = kinerja sistem tidak terpengaruh terhadap implementasi cloud computing.

4. Technology $8=$ Ketersediaan sistem yang baik akan mendukung proses aplikasi pada kesuksesan implementasi cloud computing.

Faktor baru keempat, terdiri dari indikator berikut:

1. Organization5 = Organisasi mendapatkan suatu manfaat dari implementasi cloud computing.

2. Organization6 $=$ Organisasi siap terhadap perubahan teknologi cloud computing.

3. Organization4 = Implementasi cloud computing dapat mengurangi perencaan sumberdaya yang memadai

4. Organization $2=$ Inovasi sistem cloud computing dapat mendukung kesuksesan cloud computing terhadap bisnis perusahaan.

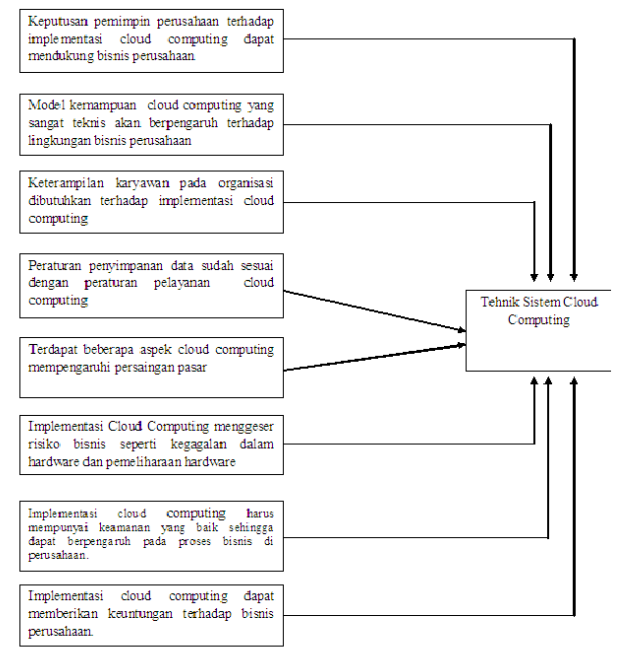

Gambar 1 Indikator dan Faktor Teknik Sistem Implementasi Cloud Computing untuk Meningkatkan Kualitas Sistem Virtual Hotel Program yang telah di implementasi Cloud Computing.

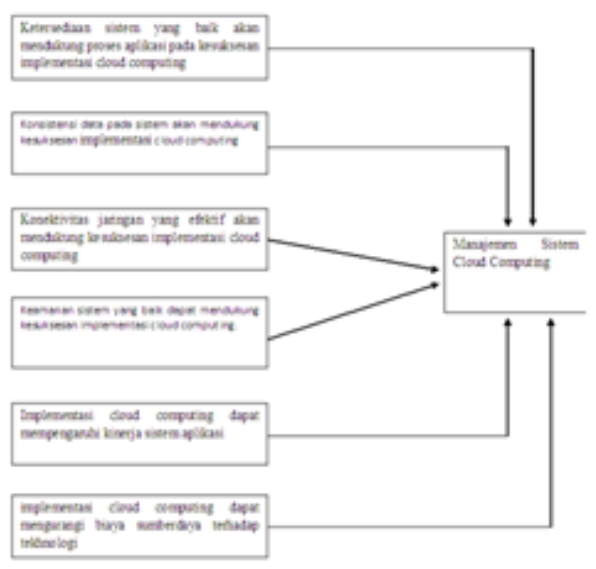

Gambar 2 Indikator dan Faktor Management Sistem Cloud Computing untuk Meningkatkan Meningkatkan Kualitas Sistem Virtual Hotel Program yang telah di implementasi Cloud Computing.

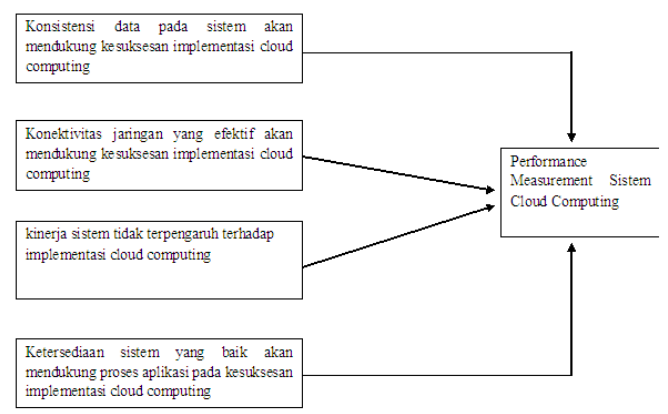

Gambar 3 Indikator dan Faktor Performance Measurement Sistem Cloud Computing untuk Meningkatkan Kualitas Sistem Virtual Hotel Program yang telah di implementasi Cloud Computing.

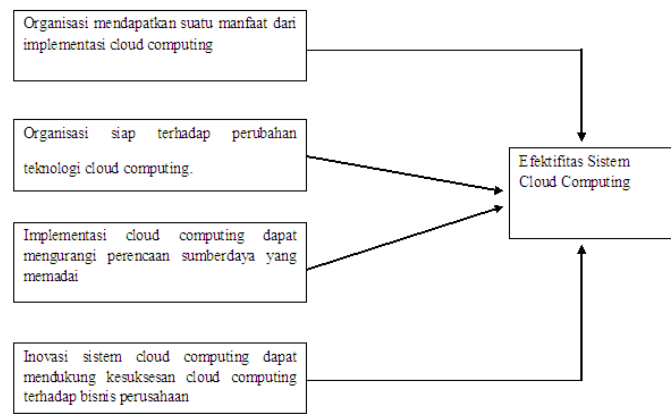

Gambar 4 Indikator dan Faktor Efektifitas Sistem Cloud Computing untuk Meningkatkan Meningkatkan Kualitas Sistem Virtual Hotel Program yang telah di implementasi Cloud Computing. 
Model yang dapat digunakan untuk mengevaluasi Implementasi Cloud Computing dapat diketahui memiliki 4 faktor baru yang dapat mempengaruhi evaluasi sistem Cloud Computing. faktor pertama Teknik Sistem Cloud Computing $\left(\mathrm{X}_{1}\right)$,Faktor kedua Management Sistem Cloud Computing $\left(\mathrm{X}_{2}\right)$, Faktor ketiga Performance Measurement Sistem Cloud Computing $\left(\mathrm{X}_{3}\right)$, Faktor keempat Efektifitas Sistem Cloud Computing $\left(\mathrm{X}_{4}\right)$, Untuk lebih jelasnya dapat dilihat pada gambar 4.8 berikut ini:

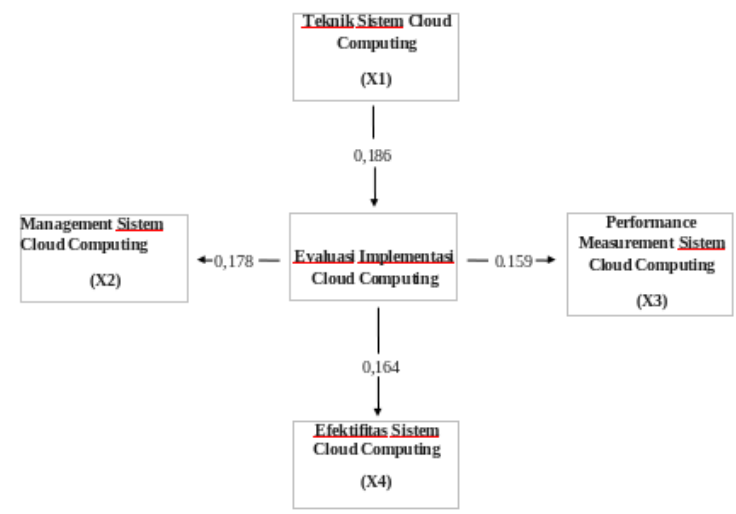

Gambar 5 Faktor dan nilai yang dapat digunakan untuk mengevaluasi Implementasi Cloud Computing.

Sumber : Hasil Analisis Penulis, 2018

Dari hasil analisis regresi yang dilakukan peneliti, maka didapatkan persamaan yang dapat digunakan untuk evaluasi Implementasi Cloud Computing di PT. Supranusa Sindata.

$Y=6,780+0,186(X 1)+0.178(X 2)+0,159(X 3)+$ $0,164(X 4)$
Memiliki batasan nilai minimum dan maksimumnya sebagai berikut:

$-3,63065 \leq 2,43796$

$-2,36836 \leq 2,280244$

$-3,17654 \leq 1,85007$

$-2,63525 \leq 3,58158$

Dari keempat faktor yang mempengaruhi kinerja dari sebuah sistem evaluasi implementasi cloud computing, dapat dilakukan analisa dengan menggunakan IT balance scorecard. Dari keempat faktor tersebut, faktor teknik sistem implementasi cloud computing, managemen sistem implementasi cloud computing, performance measurement system cloud computing, efektifitas sistem implementasi cloud computing di hubungkan dengan empat perspektif dari IT balance scorecard yaitu kontribusi perusahaan, orientasi pengguna, kesempurnaan operasional, dan orientasi masa depan.

Berdasarkan empat perspektif IT balanced scorecard tersebut, dapat dibuat rancangan IT balanced scorecard dari divisi IT terkait evaluasi sistem implementasi cloud computing yang telah diterapkan. 


\begin{tabular}{|c|c|c|c|c|c|c|}
\hline perspective & $\begin{array}{c}\text { KPI / } \\
\text { Strategy }\end{array}$ & Description & $\begin{array}{c}\text { Targe } \\
\mathbf{t}\end{array}$ & New Factor & $\begin{array}{c}\text { Code } \\
\text { Indicator }\end{array}$ & $\begin{array}{c}\text { Evaluation of } \\
\text { Implementatio } \\
\text { n of Cloud } \\
\text { Computing } \\
\end{array}$ \\
\hline \multirow[t]{3}{*}{$\begin{array}{l}\text { Contribution } \\
\text { s company }\end{array}$} & $\begin{array}{l}\mathrm{CIO} \\
\text { Innovativenes } \\
\mathrm{s}\end{array}$ & $\begin{array}{l}\text { Decision on } \\
\text { the } \\
\text { implementatio } \\
\mathrm{n} \text { of corporate } \\
\text { leaders can } \\
\text { support } \\
\text { business } \\
\text { enterprise } \\
\text { cloud }\end{array}$ & $90 \%$ & $\begin{array}{l}\text { Teknik } \\
\text { Sistem } \\
\text { Cloud } \\
\text { Computing }\end{array}$ & $\begin{array}{l}\text { Environment } \\
1\end{array}$ & Environment \\
\hline & Competition & $\begin{array}{l}\text { There are } \\
\text { several aspects } \\
\text { of cloud } \\
\text { computing } \\
\text { affect market } \\
\text { competition }\end{array}$ & $100 \%$ & $\begin{array}{l}\text { Teknik } \\
\text { Sistem } \\
\text { Cloud } \\
\text { Computing }\end{array}$ & $\begin{array}{l}\text { Environment } \\
3\end{array}$ & Environment \\
\hline & $\begin{array}{l}\text { Adequate } \\
\text { Resource }\end{array}$ & $\begin{array}{l}\text { Implementatio } \\
\mathrm{n} \text { of cloud } \\
\text { computing can } \\
\text { reduce the } \\
\text { planning of } \\
\text { adequate } \\
\text { resources }\end{array}$ & $90 \%$ & $\begin{array}{l}\text { Efektifitas } \\
\text { Sistem } \\
\text { Cloud } \\
\text { Computing }\end{array}$ & $\begin{array}{l}\text { Organization } \\
4\end{array}$ & Organization \\
\hline \multirow{3}{*}{$\begin{array}{l}\text { User } \\
\text { Orientation }\end{array}$} & $\begin{array}{l}\text { Innovativenes } \\
\mathrm{s}\end{array}$ & $\begin{array}{l}\text { Innovation } \\
\text { cloud } \\
\text { computing } \\
\text { system can } \\
\text { support the } \\
\text { success of } \\
\text { cloud } \\
\text { computing to } \\
\text { the enterprise } \\
\text { business }\end{array}$ & $100 \%$ & $\begin{array}{l}\text { Efektifitas } \\
\text { Sistem } \\
\text { Cloud } \\
\text { Computing }\end{array}$ & $\begin{array}{l}\text { Organization } \\
2\end{array}$ & Organization \\
\hline & $\begin{array}{l}\text { Culture } \\
\text { Resistance }\end{array}$ & $\begin{array}{l}\text { Organization } \\
\text { is ready to } \\
\text { change the } \\
\text { cloud } \\
\text { computing } \\
\text { technology }\end{array}$ & $100 \%$ & $\begin{array}{l}\text { Efektifitas } \\
\text { Sistem } \\
\text { Cloud } \\
\text { Computing }\end{array}$ & $\begin{array}{l}\text { Organization } \\
6\end{array}$ & Organization \\
\hline & $\begin{array}{l}\text { Perceived } \\
\text { Technical } \\
\text { Competence }\end{array}$ & $\begin{array}{l}\text { Model of } \\
\text { cloud } \\
\text { computing } \\
\text { capabilities } \\
\text { that are very } \\
\text { technical will } \\
\text { affect the } \\
\text { company's }\end{array}$ & $100 \%$ & $\begin{array}{l}\text { Teknik } \\
\text { Sistem } \\
\text { Cloud } \\
\text { Computing }\end{array}$ & $\begin{array}{l}\text { Environment } \\
2\end{array}$ & Environment \\
\hline
\end{tabular}




\begin{tabular}{|c|c|c|c|c|c|c|}
\hline & & business & & & & \\
\hline \multirow[t]{3}{*}{$\begin{array}{l}\text { the } \\
\text { operational } \\
\text { perfection }\end{array}$} & $\begin{array}{l}\text { Data } \\
\text { Management }\end{array}$ & $\begin{array}{l}\text { Good data } \\
\text { management is } \\
\text { needed in the } \\
\text { implementatio } \\
n \text { of cloud } \\
\text { computing }\end{array}$ & $100 \%$ & $\begin{array}{l}\text { Managemen } \\
\text { t Sistem } \\
\text { Cloud } \\
\text { Computing }\end{array}$ & Technology4 & Technology \\
\hline & $\begin{array}{l}\text { Efective } \\
\text { Connectivity }\end{array}$ & $\begin{array}{l}\text { Network } \\
\text { connectivity, } \\
\text { will support } \\
\text { the successful } \\
\text { implementatio } \\
\text { n of cloud } \\
\text { computing }\end{array}$ & $100 \%$ & $\begin{array}{l}\text { Managemen } \\
\text { t Sistem } \\
\text { Cloud } \\
\text { Computing }\end{array}$ & $\begin{array}{l}\text { Technology } 1 \\
0\end{array}$ & Technology \\
\hline & Scalability & $\begin{array}{l}\text { System } \\
\text { performance is } \\
\text { not affected by } \\
\text { the } \\
\text { implementatio } \\
\text { n of cloud } \\
\text { computing }\end{array}$ & $100 \%$ & $\begin{array}{l}\text { Performance } \\
\text { Measuremen } \\
\text { t Sistem } \\
\text { Cloud } \\
\text { Computing }\end{array}$ & Technology7 & Technology \\
\hline \multirow[t]{3}{*}{$\begin{array}{l}\text { a future } \\
\text { orientation }\end{array}$} & Benefit & $\begin{array}{l}\text { Organizations } \\
\text { to obtain any } \\
\text { benefit from } \\
\text { the } \\
\text { implementatio } \\
\text { n of cloud } \\
\text { computing }\end{array}$ & $100 \%$ & $\begin{array}{l}\text { Efektifitas } \\
\text { Sistem } \\
\text { Cloud } \\
\text { Computing }\end{array}$ & $\begin{array}{l}\text { Organization } \\
5\end{array}$ & Organization \\
\hline & $\begin{array}{l}\text { Availability } \\
\text { System }\end{array}$ & $\begin{array}{l}\text { Availability of } \\
\text { systems that } \\
\text { will support } \\
\text { the } \\
\text { implementatio } \\
\text { n of } \\
\text { applications } \\
\text { on cloud } \\
\text { computing }\end{array}$ & $90 \%$ & $\begin{array}{l}\text { Performance } \\
\text { Measuremen } \\
\text { t Sistem } \\
\text { Cloud } \\
\text { Computing }\end{array}$ & Technology 8 & Technology \\
\hline & $\begin{array}{l}\text { Relative } \\
\text { Advantage }\end{array}$ & $\begin{array}{l}\text { Implementatio } \\
\mathrm{n} \text { of cloud } \\
\text { computing can } \\
\text { provide } \\
\text { benefits to the } \\
\text { company's } \\
\text { business }\end{array}$ & $100 \%$ & $\begin{array}{l}\text { Teknik } \\
\text { Sistem } \\
\text { Cloud } \\
\text { Computing }\end{array}$ & $\begin{array}{l}\text { Organization } \\
3\end{array}$ & Organization \\
\hline
\end{tabular}




\section{Managerial Implications}

Penelitian ini menghasilkan 4 (empat) faktor baru dan rancangan pengukuran kinerja Sistem Virtual Hotel Program yang telah di implementasi Cloud Computing yang mengimplikasikan bagi pihak manajerial PT. Supranusa Sindata untuk dapat memperhatikan faktor-faktor dan rancangan pengukuran kinerja sistem virtual hotel program yang telah di implementasi Cloud Computing tersebut guna meningkatkan kualitas Sistem Virtual Hotel Program yang telah di implementasi Cloud Computing di PT.Supranusa Sindata. Setelah mendapatkan model yang digunakan untuk mengevaluasi implementasi Cloud Computing dan rancangan IT Balance Scorecard terbentuk, ada beberapa permasalahan yang perlu diperhatikan oleh perusahaan terkait evaluasi sistem cloud computing yang diterapkan :

1. Pemahaman karyawan terhadap implementasi cloud computing yang sudah berjalan. Dengan adanya sistem yang sudah di implementasi cloud computing maka karyawan diharuskan menyesuaikan budaya sistem yang sudah di implementasikan. Jika tidak mulai dibudayakan akan berpengaruh terhadap bisnis perusahaan. Keluhan dari client yang menggunakan sistem dikarenakan menagani suatu sistem dengan target yang tidak sesuai sehingga menyebabkan pelanggan dari client merasa kurang nyaman.

2. Berdasarkan rancangan IT balanced scorecard yang telah dibangun, perusahaan dapat menetapkan suatu target yang sesuai untuk masing-masing komponen atau dapat pula mengadopsi target sesuai dengan hasil rancangan IT balanced scorecard.

3. Kebutuhan akan pengukuran yang tepat agar dapat membantu perusahaan mencapai tujuannya. Dengan menghubungkan pengukuran evaluasi hasil implementasi cloud computing dengan kepuasan client terhadap pelanggan dan peningkatan keuntungan bisnis perusahaan.

\section{KESIMPULAN}

Faktor-faktor yang dapat mempengaruhi evaluasi implementasi Cloud Computing di PT. Supranusa Sindata, yaitu Teknik Sistem Cloud Computing, Management Sistem Cloud Computing, Performance Sistem Cloud Computing, Efektifitas Sistem Cloud Computing.
Evaluasi Implementasi Cloud Computing setelah terbentuk model baru, kemudian dilakukan analisis regresi untuk mendapatkan nilai maksimum. Berdasarkan Tabel L9. Dari lampiran. Nilai minumum dan maksimum regresi faktor, dapat diketahui bahwa faktor $\mathrm{X}_{1}$ memiliki nilai minimum 3,63065 dan nilai maksimum 2,43796 faktor $\mathrm{X}_{2}$ memiliki nilai minimum $-2,36836$ dan nilai maksimum 2,80244 faktor $\mathrm{X}_{3}$ memiliki nilai minimum $-3,17654$ dan nilai maksimum 1,85007 faktor $\mathrm{X}_{4}$ memiliki nilai minimum $-2,63525$ dan nilai maksimum 3,58158. Dengan menggunakan model dibawah ini.

$$
\begin{gathered}
Y=6,780+0,186(X 1)+0.178(X 2)+0,159 \\
(X 3)+0,164(X 4)
\end{gathered}
$$

Dapat diketahui batasan nilai minimum dan maksimumsebagai berikut:

$$
\begin{gathered}
-3,63065 \leq 2,43796 \\
-2,36836 \leq 2,280244 \\
-3,17654 \leq 1,85007 \\
-2,63525 \leq 3,58158
\end{gathered}
$$

IT balanced scorecard yang disusun untuk mengevaluasi implementasi cloud computimg dapat digunakan untuk mengukur kinerja bisnis perusahaan dari evaluasi sistem implementasi cloud computing di perusahaan. KPI yang digunakan dalam setiap perspektif dari IT balanced scorecard disusun berdasarkan faktor-faktor yang mempengaruhi implementasi cloud computing

\section{REFERENSI}

[1] Asli Deniz Helvacioglu Kuyucu. (CIO Inovativeness) Exploring PolicyFormulation for SMEs in Cloud Computing. IBIMA Vol. 2011 (2011)

[2] Cram, Alec. 2007. The IT Balanced Scorecard Revisited. Information Systems Control Journal, Vol 5, 2007, ISACA

[3] Chinyao Low, Yahsueh Chen. (Relative Advantage) Understanding of determinants of cloud computing adoption. Vol 111 Iss:7 , pp.1006-1023

[4] Dr.Dothang Truong,Fayetteville State University,Fayetteville,NC (2010). How 
Cloud Computing Enhances Competitive Advantages : A Reasearch Model for Small Buinesses Vol 15, Num 1, Summer 2010

[5] Easwar Krisnha,Arathi KKrishnan, Gaurav Shareen, and Tapan Panda. (Market Scope) Sectorial Adoption Analysis of Cloud Computing by Examining the Dissatisfier Landscape. Vol.16 Issue 3 211-219 2013

[6] Echols dan Shadily, 2000 : 220 Pengolahan data evaluasi

[7] Gunardi, Dedi Sulistyo S., Taryana Suryana 2012. Usulan Peta Strategi Teknologi Informasi Menggunakan Pendekatan Analisis Critical Success Factor (CSF) dan IT Balanced Scorecard (Studi Kasus Pada PT. Sola Gratia Bandung). Jurnal Majalah Ilmiah Unikom, Vol 10 No. 1 Pebruari 2012, Universitas Komputer Indonesia Bandung.

[8] Ioana Catinean, Candea. (Perceived Technical Competence) Characteristic of the cloud computing model as disruptive innovation. Vol. 14, Issues 5, December 2013.

[9] Jiunn-woei lian, David C.yen, Yen - ting Wang. Top Management Support an eploratary study to understand the critical factors affecting the decision to adopt cloud computing 34 (2018) 28-36

[10] Malaty,Somasundaram,Kduraiswamy (Performance Software) Performance Improvement in Cloud Computing Using Resource Clustering. ISSN 1549-3636 2013

[11] Mathews Z.Nkhoa and Duy P.T. Dang. (Cloud Security) Contibuting Factors of Cloud Computing Adoption. Vol 1, No. 1,2013 ISSN :2289:309

[12] Maula, Khikmatul \& Ghozali, Khakim. 2012. Evaluasi Kinerja IT pada PT. XYZ Menggunakan IT Balanced Scorecard. Jurnal Teknik Pomits, Vol 1 No. 1, ITS.

[13] Mohammad Nahavi. (Data Management) Cloud Computing as an Inovation in GIS \& SDI. 2012,4, 597-607

[14] Mulyadi, "Balanced Scorecard", Jakarta: Salemba Empat, 2001.
[16] John Ngugi Makena. (Complexity) Factors that affect cloud computing adoption by small and medium enterprises in Kenya. Volume 2-Issue 5, 517-521 2013

[17] J Ranald.I.Lumsden,Anabel dan Guitierrez. (Compatibility) Understanding the Determinannts of Cloud Computing Adoption within the UK Oktober 17-18 2013,Windsor,United Kingdom

[18] Kaplan, Robert S., Norton, David P., "Balanced Scorecard, Translating strategy Into Action", Boston-Massachussets: Harvard Bussiness School Press, 1996.

[19] Karyanus Daely, Ujian Sinulingga, Asima Manurung. Analisis Statistik Faktor-Faktor yang mempengaruhi indeks prestasi mahasiswa. Saintia Matematika Vol. 1, No.5 (2013), pp.483-494.

[20] Keyes, J. (2005). Implementing the IT Balanced Scorecard: Aligning IT with Corporate Strategy. Boca Raton: Auerbach Publications.

[21] Krishnadas Nanath (2013) dan Radhakrishna (2013). A Model for Cost - Benefit Analysis of Cloud Computing Vol 22, Number 32013

[22] Sandy Kosasi. Pengukuran kinerja WebBrinet System dengan Metode IT Balanced Scorecard. Program Studi Sistem Informasi STMIK Pontianak.

[23] Sarna, David E. Y.2012. Implementing and Developing Cloud Computing Applications.United States: Taylor and Francis Group, LLCsi.

[24] Sugiyono. (2007). Statistik Untuk Penelitian. Bandung: Alfabeta.

[25] Sugiyono. 2013. Metodologi Penelitian. Bandung: Alfabeta.

[26] Setiawan, Apep, “Analisis Kinerja Perusahaan Dodol Olimpic Garut Dengan Balanced Scorecard”, Tugas Akhir Jurusan Tekhnik Dan Manajemen Industri Sekolah Tinggi Teknologi Garut, 2011. 
[27] Taniredja, tukiran (2011). Penelitian kuantitatif (sebuah Pengantar). Alfabeta. Bandung.

[28] Thomas Sommer. (Adequate Resource) Cloud Computing in Emergencing Biotech and Pharmaceutical Companies. Communication Of the IIMA Volume 13 Issues 32013.

[29] Wijaya, Rahmadi. 2007. Analisis Model IT Menggunakan Balanced Scorecard untuk
Pengembangan Sistem Teknologi Informasi. Jurnal Sistem Informasi, ISSN: 1907-1221, Vol 2 No. 1 Maret 2007, Universitas Kristen Maranatha Bandung.

[30] Yazn Alsha Maila and Savvas Papagiannidis. (Innovativeness) Cloud Computing Adoption by SMEs in the nort east of England Journal enterprise information management vol 26 Iss: 3, pp.250-275 